Article

\title{
Stability Analysis of Expansive Soil Slope Considering Seepage Softening and Moistening Expansion Deformation
}

\author{
Siyi Zhao ${ }^{1,2}$, Zhenming Shi ${ }^{1,2}$, Ming Peng ${ }^{1,2, *}$ and Yanni Bao ${ }^{3, *}$ \\ 1 Department of Geotechnical Engineering, College of Civil Engineering, Tongji University, \\ Shanghai 200092, China; 1710174@tongji.edu.cn (S.Z.); 94026@tongji.edu.cn (Z.S.) \\ 2 Key Laboratory of Geotechnical and Underground Engineering of Ministry of Education, Department of \\ Geotechnical Engineering, Tongji University, Shanghai 200092, China \\ 3 University Architectural Design Research Institute (Group) Co., Ltd., Shanghai 200092, China \\ * Correspondence: pengming@tongji.edu.cn (M.P.); smilenini@163.com (Y.B.); Tel.: +86-021-65982227 (M.P.)
}

Received: 5 May 2020; Accepted: 2 June 2020; Published: 11 June 2020

\begin{abstract}
Expansive soil is a kind of clay soil that expands rapidly after being immersed in water and shrinks significantly after losing water. The expansive soil slopes exposed to the atmosphere are in the process of continuous dry and wet cycles and are extremely unstable under the conditions of rainfall. Based on saturated-unsaturated seepage theory, the unsaturated seepage process and humidification process of the expansive soil slope under rainfall were simulated, and a related FORTRAN language program was developed. The effects of matrix suction changes, seepage softening, and moistening expansion during the seepage process were considered. The effects of strength attenuation, seepage softening, and moistening expansion on the overall stability of the expansive soil slope were analyzed. The results show that under the action of rainfall, the failure mode of the expansive soil slope after multiple dry-wet cycles is shallow collapse, and the failure surface is located in the weathered area, which is quite different from the traction landslide of the homogeneous expansive soil slope. After considering the moistening expansion and softening effects, the maximum displacement of the slope increased by an order of magnitude, and the safety factor decreased significantly. The significant increase in the horizontal stress of the lower half slope is the main reason for the landslide. The research results well explain the special tractive and shallow properties of typical expansive soil landslides.
\end{abstract}

Keywords: expansive soil; landslide; rainfall; dry-wet circle; unsaturated soil

\section{Introduction}

Expansive soil is a special soil widely distributed all over the world. Expansive soils have been found in more than 40 countries around the world, covering six continents. It has obvious water-absorbing expansion, multi-crackness, and strength attenuation. During rainfall and intermittent periods, the expansive soil repeatedly absorbs water and expands, shrinking due to water loss and resulting in a large number of cracks. The expansive soil slope exposed to the atmosphere undergoes a dry-wet cycle that generates a large number of cracks, and the shear strength is significantly reduced. Under the action of rainfall, the suction of the expansive soil matrix decreases moistening expansion occurs, and it softens, which can easily cause the instability of various roadbed slopes and bring serious harm to highway construction.

A lot of research has been carried out on the influence of dry-wet cycle on the strength of expansive soil and the slope stability. In the aspect of strength research of expansive soil, $\mathrm{Xu}$ Bin [1] found that the cohesion and internal friction angle decreased in hyperbolic relation with the number of dry and 
wet cycles, and the strength parameter decreased most obviously after the first 1 2 cycles. It was suggested that the strength after 3 dry and wet cycles should be used as the design parameter of fracture development area. Wu Junhua [2] carried out a large-scale shear test on expansive soil in the field. It was found that, with the increase of the number of dry-wet cycles, the main cracks first formed, and then the new small cracks formed, which made the soil surface fragmented, and the cohesion reduced by $50 \%$. Yang Heping [3] selected a Nanning expansive soil sample, set a reasonable test load and dry-wet cycle conditions, and analyzed the shear strength attenuation law of expansive soil.

In the field observation and model test, $\mathrm{Ng} \mathrm{C} \mathrm{W} \mathrm{W} \mathrm{[4]} \mathrm{and} \mathrm{Zhan} \mathrm{Liangtong} \mathrm{[5]} \mathrm{conducted}$ field or indoor artificial rainfall simulation tests on unsaturated expansive soil slopes to derive the rainfall infiltration law of the slopes and pointed out that the internal mechanism of the instability of the expansive soil slope is the decrease of matrix suction and the deformation of moistening expansion. Greco [6] studied the stability of expansive soil slopes under rainfall infiltration and systematically analyzed the relationship between rainwater infiltration depth, landslide, and moisture content, as well as the expansion of the infiltration line. Wang Guoli [7] used a centrifugal model test to study the stability of expansive soil slope under the condition of dry and wet cycles. It was found that the cracks gradually developed with the increase of dry and wet cycles, reducing the shear strength of soil and providing a fast channel for rainwater infiltration, and eventually lead to progressive failure of the slope. Yin Zongze [8] divided the expansive soil slope into three layers: completely weathered layer, semi-weathered layer, and non-weathered layer. He gives the approximate determination method of the strength parameters of each layer but does not consider the influence of the expansibility, so the calculated stability coefficient is too large. Cheng et al. [9] studied the small-scale expansive soil slope model under rainfall infiltration and found that its shallow failure has obvious traction and multiple sliding properties, and slope instability is mainly controlled by expansion deformation.

In the aspect of theory and numerical simulation, the most famous constitutive model of expansive soil is the Barcelona expansion model (BExM) proposed by Alonso $[10,11]$ in 1999 . The theory of the model is rigorous, and complex boundary conditions, such as dry-wet cycle, can be considered, but the model is too complex. The BExM model involves as many as 20 parameters. It needs a lot of unsaturated triaxial tests and isobaric consolidation tests under the condition of controlled suction, which limits the further application of the theoretical model in engineering practice.

Qi S [12] carried out a numerical simulation of the swelling process of expansive soil under rainfall conditions based on the similarity of heat conduction and seepage. However, the influence of the decrease of substrate suction, the weight of rainwater, and the softening effect of soil during the rainfall were not considered.

SUN Jichao [13] simulated the expansion force of expansive soil due to the effect of humidification and expansion by applying an external force perpendicular to the air surface on the unit. However, the expansion and deformation of the soil develops in all directions, and it is not reasonable to apply it to the direction of the vertical facing surface.

Hicks, M. A $[14,15]$ studied the influence of heterogeneity on the reliability and failure of two-dimensional and three-dimensional long slopes by finite element method. He found that the change of parameters has an important influence on the stability and failure mode of the slope. Expansive soil slope is a typical heterogeneous clay slope. His research put forward a new method for expansive soil slope.

Double-porosity media are composed of two distinct regions with contrasted hydraulic parameters. The permeability coefficient of expansive soil is different between the weathering area and the unweathered area, which is a typical double-porosity medium. J Lewandowska [16] performed deep research on the unsaturated seepage characteristics of this medium and proposed a new method for the seepage problem of expansive soil.

In summary, expansibility and strength attenuation are the two most critical factors affecting the stability of expansive soil slopes, but the current research fails to consider the effects of both at the same time. In view of the above deficiencies, this article first studied the attenuation law of 
the strength of expansive soil through laboratory experiments. Through unsaturated seepage theory, the processes of rainfall infiltration and matrix suction reduction of expansive soil slopes were simulated. Based on the theory of humidity field, the FORTRAN program was developed, and the effects of wetting and drying cycle, moistening absorption expansion, and soil softening on the stability of the slope were considered reasonably. Thus, the change law of stress displacement and stability of the swelling soil slope under the effect of rainfall humidification was analyzed comprehensively. Overall, this study provides a better method to evaluate the stability of expansive soil excavated in rain and dry conditions.

\section{Material and Methods}

\subsection{Soil Sample Selection and Basic Soil Properties}

As shown on the right of Figure 1 below, the sample of expansive soil is taken from the site of Qingbao Road, Baoshan City, Yunnan Province. The soil layers along the line are mainly Quaternary arable soil (q4pd), Quaternary alluvial and proluvial clay (q4al + q4pl), and Upper Tertiary clay (N2). Among them, the third layer of soil (QAL + PL) is continuously distributed along the road, with an average buried depth of $0.5 \mathrm{~m}$ and an average thickness of $7.9 \mathrm{~m}$, which is the main bearing layer of the embankment. The clay in this layer is brownish gray or grayish yellow, plastic, and easy to soften when encountering water, with shallow mud cracks developed.
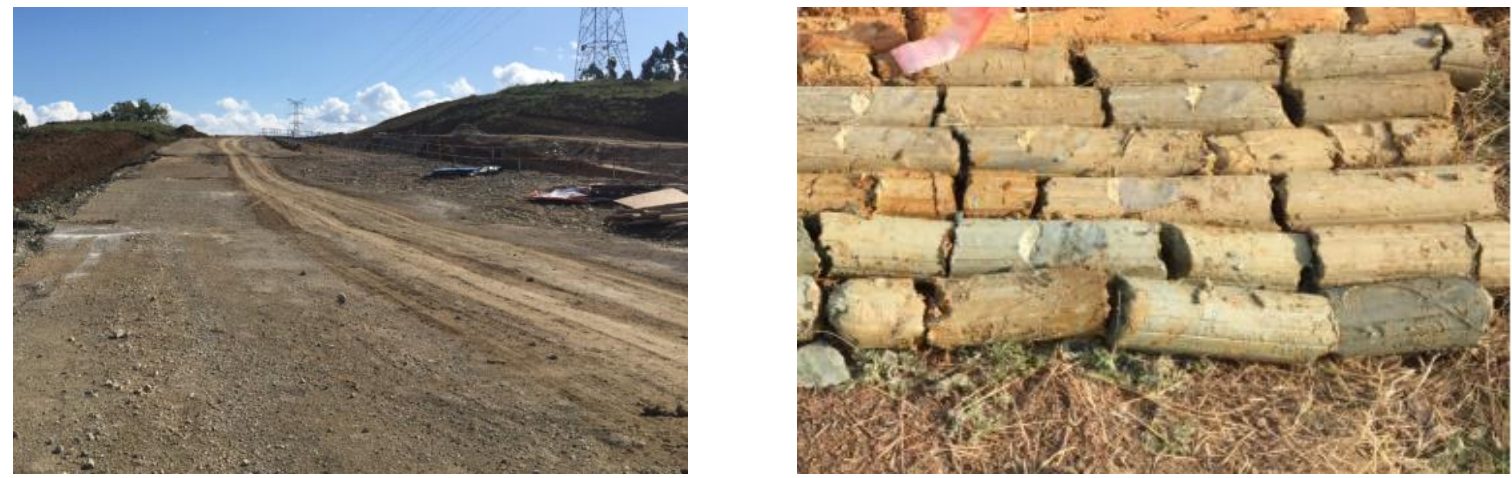

Figure 1. Project site and typical soil sample.

Before the dry and wet cycle test, a series of soil tests shall be carried out first. The basic parameters of soil properties are shown in Table 1. According to relevant specifications, the expansion grade is medium.

Table 1. Basic properties of Baoshan expansive soil.

\begin{tabular}{cc}
\hline Parameters & Value \\
\hline water content $\mathrm{w} / \%$ & 37.1 \\
natural density $\rho$ & 1.83 \\
void ratio e & 1.02 \\
saturation $\mathrm{S}_{\mathrm{r}}$ & 95.7 \\
plastic limit $\mathrm{w}_{\mathrm{p}} / \%$ & 51.3 \\
liquid limit $\mathrm{w}_{\mathrm{l}} / \%$ & 27.9 \\
Free expansion rate $/ \%$ & 67 \\
\hline
\end{tabular}

\subsection{Dry-Wet Cycle Test}

\subsubsection{The Process of Dry and Wet Cycle}

Before the dry and wet cycle test, the samples shall be numbered and weighed, and the natural mass of each sample shall be recorded. The number of scheduled wet and dry cycles is $0 \sim 5$ times. 
Therefore, 6 sets of soil samples should be prepared, and each 10 soil samples should be used as a group for dry and wet cycles. The upper and lower sides of the sample are covered with a piece of filter paper and a permeable stone to prevent the soil particles from scattering during the water shrinkage process. The sample was placed in a water tank, and the tank was filled with water until it was level with the permeable stone at the bottom of the sample.

In order to simulate the saturated process of rainfall infiltration in nature, spray water on the permeable stone with a spray bottle for 5 times a day, until the water is no longer absorbed by the sample. Repeat for 3 days, that is, complete the saturated process of the sample once.

Weight of each sample after water absorption saturation confirms that the sample is close to full saturation ( $\geq 98 \%$ ). During the drying process, the sample was dehydrated in the oven. The temperature in the oven was set to $40{ }^{\circ} \mathrm{C}$ (the highest temperature simulated in the natural environment), and the sample was dried for $24 \mathrm{~h}$. In this way, a dry and wet cycle was completed. The 6 groups of samples underwent $0 \sim 5$ cycles of dry and wet respectively.

\subsubsection{Measurement of Strength and Permeability Coefficient}

Before the test, wet the dry sample to natural humidity. The operation steps are as follows:

(1) Place the sample that has completed the predetermined number of dry and wet cycles in the humidification box (the sample has been weighed and marked before the test).

(2) The test quality is measured continuously during humidification.

(3) When the mass increases to the mass of soil sample without drying and wetting cycle, the humidification shall be stopped.

The strength of expansive soil sample is measured by direct shear test. The samples which had completed the predetermined number of dry and wet cycles and humidified to natural moisture content were loaded into the shear box of the direct shear tester and applied the corresponding vertical pressure to measure the shear strength in the direct fast shear test. In the shear process, 50, 100, 200, and $300 \mathrm{kPa}$ vertical pressures were applied on the soil samples, respectively.

Because the unsaturated permeability coefficient is very difficult to measure, Qy1-3 permeameter was used in this test to measure the saturated permeability coefficient of expansive soil. The filter paper is pasted on the top and bottom of the sample and placed between two permeable rocks. The sample is clamped with a saturated frame and placed in a saturator for vacuum saturation (vacuum for 1-2 $\mathrm{h}$; saturation for $12 \mathrm{~h}$ ), making it close to the natural saturation of the aquifer. The sample was put into the test tank of QY1-3 osmotic pressure instrument consistent with the specifications of ring knife, and the saturated permeability coefficient of soil sample was measured under the appropriate $40 \mathrm{kPa}$ osmotic pressure.

\subsection{Weathering Fracture}

The crack development of soil samples was observed after each dry and wet cycle. Figure 2 shows the crack expansion of samples after $0 \sim 5$ dry and wet cycles. 


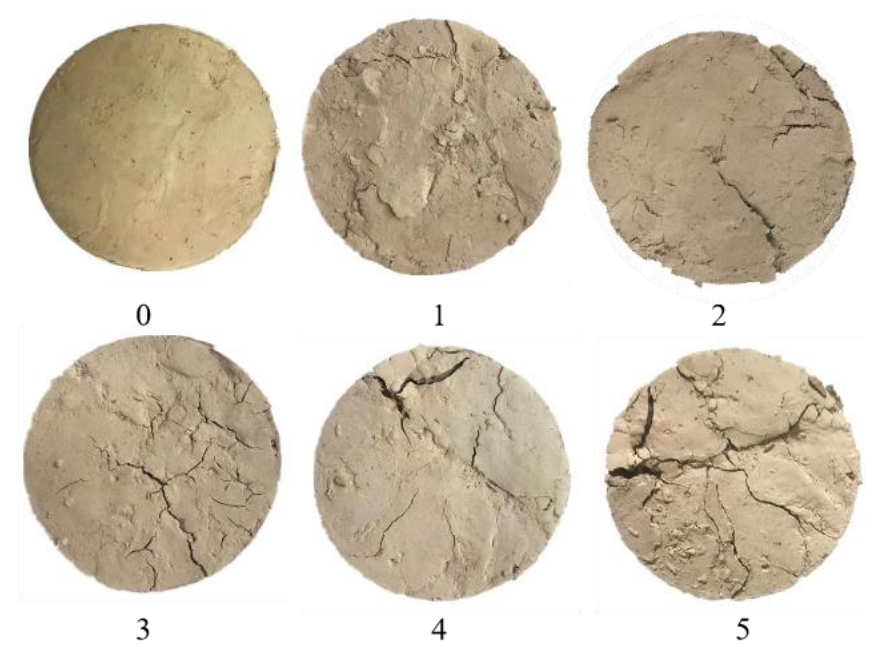

Figure 2. The surface cracks and the number of dry-wet cycles.

After one dry and wet cycle, dry shrinkage cracks appear on the surface of the sample. With the increase of the number of dry and wet cycles, new cracks keep forming and expand in both the surface and interior directions. After three dry and wet cycles, a network of cracks had formed on the surface of the soil, and a penetrating crack had formed inside the test. After 4 cycles of dry and wet, the number of cracks did not increase obviously, and the width of one of the cracks increased obviously and formed the main crack. After five cycles of dry and wet, the number of micro-cracks on the surface of the sample increased further, while the main cracks expanded slightly, approaching the degree of fracture of the strongly weathered zone.

In order to get quantitative index of the degree of crack initiation, the surface crack rate of the sample was calculated. With the development of computer software and imaging technology, fracture imaging technology and surface fracture rate calculation method are more convenient.

The procedure for calculating the area fracture rate is as follows:

(1) The crack photo is shown in Figure 3, the left is the original picture; the right is the processed binarized picture. Image processing software Photoshop is used to binarize the crack image, that is, the part of the crack in the image is represented by black, and the rest of the irrelevant part is represented by white.

(2) In order to ensure the accuracy of the processing effect, the binary image after processing is compared with the original image to eliminate the wrong non-fracture area (for example, the uneven part of the surface).

(3) Count the number of black pixels in the whole image, according to Equation (1), and we can get the fracture quantitative index, surface fracture rate.

$$
\delta_{\mathrm{f}}=\frac{\sum_{\mathrm{i}=1}^{\mathrm{n}_{\mathrm{i}}} A_{\mathrm{i}}}{A} .
$$

In the above formula, $\delta_{\mathrm{f}}$ is the area crack rate, $A$ is the area of statistical sample, $\mathrm{n}_{\mathrm{i}}$ is the total number of cracks, and $A_{\mathrm{i}}$ is the area occupied by the crack. 

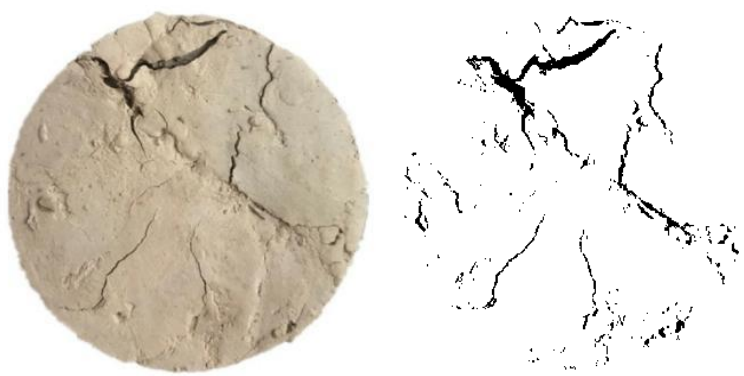

Figure 3. Image of fissures after binarization (the left is the original picture; the right is the processed binarized picture).

It can be seen from Figure 4 that the influence of the 1st 2nd circle on soil sample crack is the most obvious, and the change amplitude of surface crack rate is the largest. The last two cycles have little effect on the fracture rate.

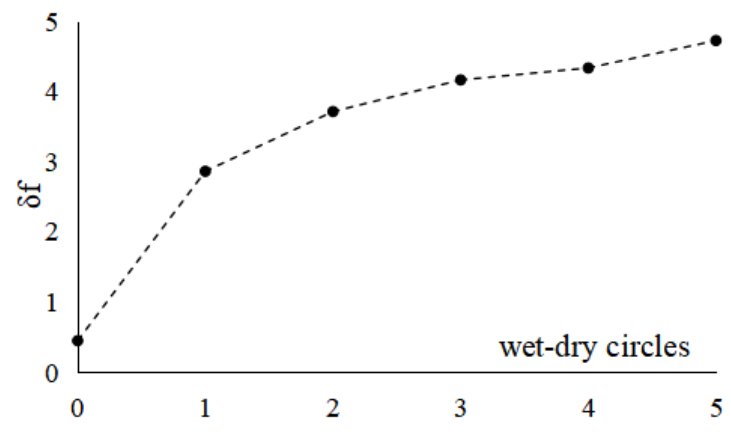

Figure 4. Fissures area ratio changes under wetting and drying cycles.

Figure 5 shows the cracks on the surface of the expansive soil at the project site, similar to the cracks in the laboratory sample. Under the natural environment, the surface expansive soil continuously undergoes the dry and wet cycle. While the surface cracks develop in a network, there are usually 1 or 2 groups of dominant cracks, in which width and depth are significantly larger than other cracks.

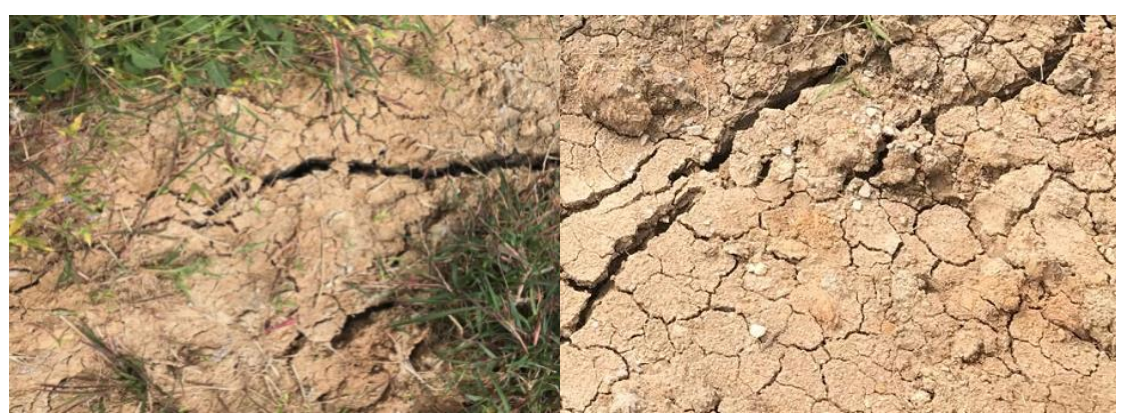

Figure 5. Surface cracks of expansive soil in site.

The main crack has a large opening degree near the surface, which reduces the constraint on the lateral soil mass. Under the action of rainfall, a large amount of rainfall infiltrates into the cracks, producing infiltration force and hydro-static pressure, and increasing the downward force of the slope. The strength of expansive soil decreases from unsaturated to saturated. Therefore, under the influence of rainfall and other construction disturbances, the main crack is easily expanded further, forming a failure surface and causing the overall instability of the slope. 


\subsection{The Influence of the Number of Dry and Wet Cycles on Strength Parameters}

The relationship between the number of dry and wet cycles and shear strength is shown in the Figure 6 below. According to the test results, the number of dry and wet cycles has a great influence on the shear strength of expansive soil. After the first one or two cycles of dry and wet soil, the strength of expansive soil decreased most significantly. With the formation and expansion of cracks, the soil was gradually close to crushing, and the cohesive force was continuously reduced. After three dry and wet cycles, the shear strength of soil tends to be stable.
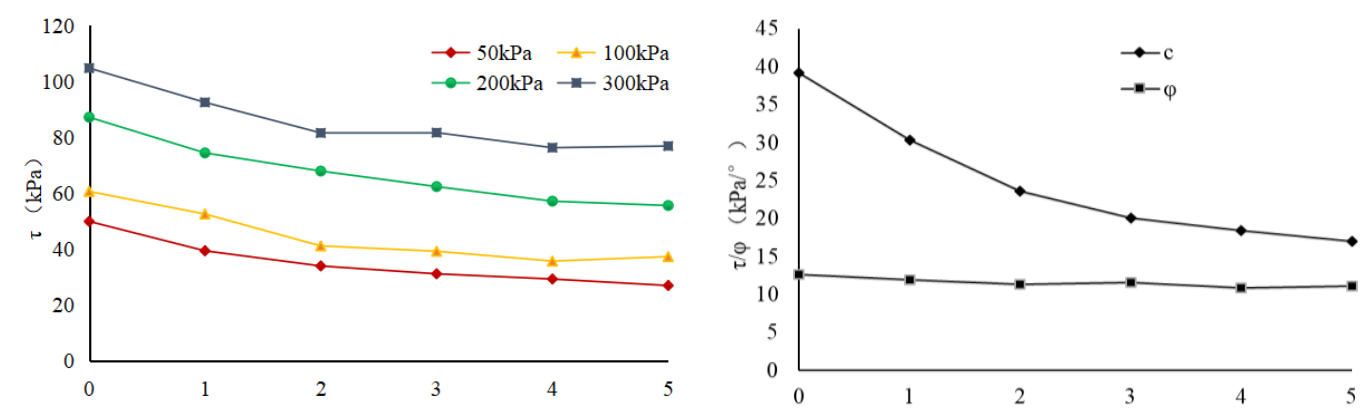

Figure 6. The relationship between shear strength and the number of wet-dry cycles.

After the first 1 2 cycles of drying and wetting, there are a lot of cracks in the sample due to the expansion and contraction process. The generation of these cracks reduces the cohesion formed by the cementation of soil particles, which leads to the decrease of the cohesion of the expansive soil sample with the increase of the number of cycles of drying and wetting. After the last $4 \sim 5$ cycles, the soil has completely cracked, so the surface rupture rate and cohesion have not changed significantly.

After 5 wet and dry cycles, the attenuation amplitudes of $\mathrm{c}$ and $\varphi$ were $55.8 \%$ and $13.7 \%$, respectively, and the final strength indexes were $\mathrm{c}=17.1 \mathrm{kPa}$ and $\varphi=11.2^{\circ}$, respectively. The dry-wet cycle does not have a significant effect on the internal friction angle because the internal friction angle $\varphi$ is a parameter reflecting the frictional characteristics between the soil particles. When there is no obvious particle breakage or directional arrangement in the expansive soil, the internal friction angle will not be greatly reduced (Table 2).

Table 2. Attenuation rate of strength parameters.

\begin{tabular}{ccccc}
\hline Dry-Wet Cycles & $\mathbf{C ~ ( K p )}$ & Attenuation (\%) & $\mathbf{\Phi ( { } ^ { \circ } )}$ & Attenuation (\%) \\
\hline 0 & 38.67 & 0 & 12.96 & 0 \\
1 & 30.36 & 21.49 & 11.93 & 7.95 \\
2 & 23.71 & 38.69 & 11.31 & 12.73 \\
3 & 20.05 & 48.15 & 11.62 & 10.33 \\
4 & 18.30 & 52.67 & 10.90 & 15.90 \\
5 & 17.11 & 55.75 & 11.18 & 13.73 \\
\hline
\end{tabular}

The increase of surface fracture rate is similar to the decrease of cohesion. After the first 1 2 cycles of drying and wetting, there are a lot of cracks in the sample due to the expansion and contraction process. The generation of these cracks reduces the cohesion formed by the cementation of soil particles, which leads to the decrease of the cohesion of the expansive soil sample with the increase of the number of cycles of drying and wetting. In the last $4 \sim 5$ cycles, the soil sample has been disintegrated, so the surface fracture rate and cohesion have not changed obviously.

\subsection{The Influence of the Number of Dry-Wet Cycles on the Permeability Coefficient}

The Figure 7 shows that the change law of saturated permeability coefficient of expansive soil is just opposite to cohesive force. After the first 1-2 cycles, the permeability coefficient increased most 
significantly, reaching more than 10 times. After the last 3 to 5 cycles, the permeability coefficient tends to be stable.

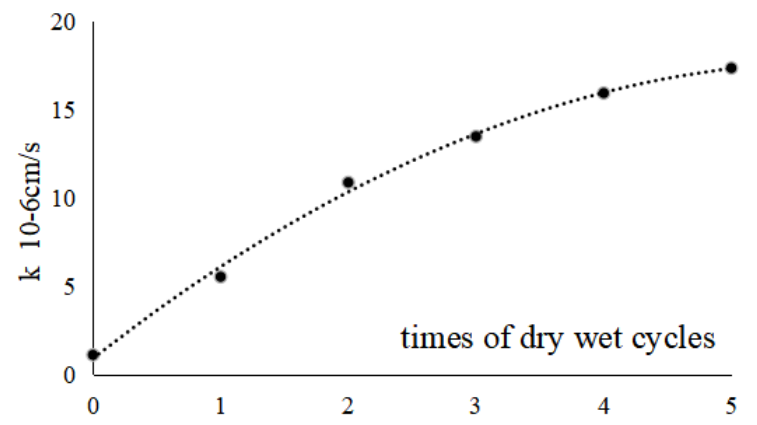

Figure 7. The relationship between $\mathrm{k}_{\text {sat }}$ and the number of wet-dry cycles.

By observing the internal cracks of the sample after each dry-wet cycle (Figure 8), it can be found that the main reason for the above results is the penetration of the main cracks after the first three dry-wet cycles. The width of the main crack is several times that of other cracks, and it is the first to pass through the upper and lower cracks and becomes the fast channel of water infiltration, which has a decisive influence on the increase of permeability coefficient of the sample.

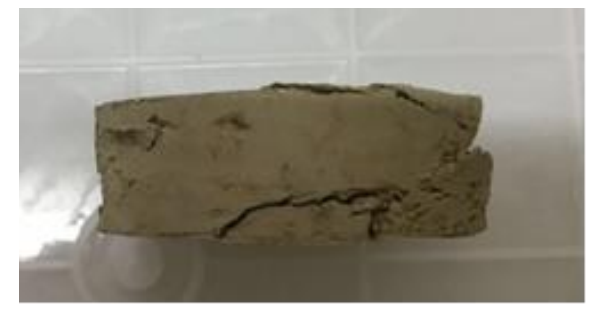

Figure 8. External cracks of specimens after three dry-wet cycles.

After 4 to 5 cycles, the surface looseness of the sample increased. Since the main fissure has been formed and penetrated, the further expansion of other fissures is restricted. There is no new penetrating crack in the soil sample, and the new small crack will not have a significant impact on the permeability coefficient of the soil. Therefore, the permeability coefficient of the specimen increases slowly and eventually tends to be stable.

\section{Related Theories}

\subsection{Consideration of Unsaturated Seepage Characteristics}

The theory of saturated seepage sets the pore pressure of unsaturated zone to 0 by default in seepage calculation, which cannot consider the influence of matrix suction. In fact, the matrix suction has a great influence on the shear strength of unsaturated soil. Therefore, the influence of suction should be considered in seepage analysis.

According to the consolidation theory of single-phase flow, it is assumed that pore gas is discharged instantaneously. The influence of pore water pressure and matrix suction on pore fluid is ignored. According to the principle of bishop effective stress [17], the stress relationship can be simplified as follows:

$$
\sigma_{\mathrm{ij}}=\sigma_{\mathrm{ij}}^{\prime}+\chi p_{w} .
$$

In formula (1), $\sigma_{\mathrm{ij}}$ is the total stress, $\sigma^{\prime}{ }_{\mathrm{ij}}$ is the effective stress, $P_{w}$ is the pore water pressure, and $\chi$ is the effective stress parameter. To simplify, saturation ( $\mathrm{Sr}$ ) is used instead.

The matric suction of expansive soil samples was measured by filter paper method and fitted by VG (van Genuchten) model [18]. After fitting, the parameters A and B of VG model are $2.2 \times 10^{4}$ and 
0.5 respectively. In addition, according to the relevant research, the effect of dry-wet cycles on the soil water characteristic curve(SWCC) of expansive soil is not obvious [19], so it is assumed that the soil water characteristic of expansive soil will remain unchanged after the dry-wet cycles.

The permeability coefficient of unsaturated zone is a function of saturation, which is calculated according to the following empirical formula [20].

$$
\mathrm{K}(\mathrm{s})=\mathrm{K}_{\mathrm{sat}} \times \mathrm{Sr}^{2 *}(3-2 \mathrm{Sr}) .
$$

Unsaturated permeability coefficient $(\mathrm{K})$ can be defined as a function of saturation. In the above formula, $\mathrm{s}$ is the saturation of soil and $\mathrm{k}_{\mathrm{sat}}$ is the saturation permeability coefficient.

\subsection{Moistening Expansion}

At present, the theory of moisture field can be used for reference in the analysis of swelling process of expansive soil. The theoretical basis is that there is a certain similarity in principle between the heat conduction process and the percolation process of the liquid, which provides a possibility for using the temperature field to simulate the humidity field. At the same time, the endothermic expansion of material can be used to simulate the process of water absorption expansion of expansive soil [21].

The unsaturated seepage differential equation is:

$$
\frac{\partial}{\partial x}\left(k_{x} \frac{\partial h_{m}}{\partial x}\right)+\frac{\partial}{\partial y}\left(k_{y} \frac{\partial h_{m}}{\partial y}\right)+\frac{\partial}{\partial z}\left(k_{z} \frac{\partial h_{m}}{\partial z}\right)=C_{w} \frac{\partial h_{m}}{\partial t} .
$$

$k_{x}, k_{y}$, and $k_{z}$ are the permeability coefficients in three directions, $\mathrm{hm}$ is the suction head of the matrix, and $C w$ is the slope of the tangent line at a point on the soil water characteristic curve. For the heat conduction problem, the heat conduction differential equation obtained by the simultaneous heat energy balance equation and the Fourier heat conduction equation is:

$$
\frac{\partial}{\partial x}\left(\lambda_{x} \frac{\partial T}{\partial x}\right)+\frac{\partial}{\partial y}\left(\lambda_{y} \frac{\partial T}{\partial y}\right)+\frac{\partial}{\partial z}\left(\lambda_{z} \frac{\partial T}{\partial z}\right)=\rho C_{v} \frac{\partial T}{\partial t} .
$$

Comparing Equations (3) and (4), we can see that the unsaturated seepage differential equation and the heat conduction differential equation are similar. Among them, the permeability coefficient $k$ corresponds to the thermal conductivity coefficient $\lambda$; the matrix suction head $h_{m}$ corresponds to the temperature $T$; the specific water weight corresponds to the specific heat capacity, and the seepage speed corresponds to the heat conduction speed. Therefore, the temperature field can be used to simulate the process of rainfall and humidification, but it must be pointed out that, without improvement, this method cannot consider the effects of reduced suction and soil softening.

For expansive soils, it is assumed that there is a linear relationship between expansive deformation and moisture content. The relationship between the expansive deformation and moisture content change during humidification is:

$$
\Delta \varepsilon_{i j}=\beta \delta_{i j} \Delta w .
$$

The thermal expansion equation for the thermal expansion of an object in thermodynamics is:

$$
\Delta \varepsilon_{i j}=\alpha \delta_{i j} \Delta T
$$

The equivalent moistening expansion coefficient $\alpha$ can be obtained by the above two formulas:

$$
\alpha=\frac{\beta \Delta w}{\Delta T} .
$$

The basic idea of using temperature field to simulate the expansion process of expansive soil is as follows: 
1. The rainfall boundary is applied to the model to obtain the humidity field of the slope after rainfall.

2. According to the equivalence of the humidity field and temperature field parameters, a reasonable equivalent moistening expansion coefficient is obtained by inversion. Assuming that the unit water content is equal to the residual water content, the equivalent temperature is $0{ }^{\circ} \mathrm{C}$. The equivalent temperature when fully saturated is $100{ }^{\circ} \mathrm{C}$. The equivalent temperature $T_{p}$ between them is calculated by linear interpolation, and the calculation formula is:

$$
T_{\mathrm{p}}=100 \times \frac{\Delta \theta}{\theta_{\mathrm{s}}-\theta_{\mathrm{r}}} .
$$

The change of moisture content before and after rainfall is calculated, which is transformed into the change of equivalent temperature, and the moistening expansion strain is calculated. The moistening expansion is added to the total strain in the form of additional strain to update the total strain of the slope, as follows:

$$
\varepsilon_{i j}=\varepsilon_{i j}^{\sigma}+\varepsilon_{i j}^{s} .
$$

According to the new strain field, the total stress and effective stress of each element are calculated through deformation coordination and stress balance conditions, and the stress and strain of the whole slope are updated. The above is the main theory of humidity stress field theory, which is based on the similarity between endothermic expansion and moisture expansion.

\subsection{Seepage Softening Effect}

The strength of expansive soil is closely related to the water content. In the area of expansive soil, changes in water content of expansive soil due to climate rainfall will inevitably lead to changes in its strength. For this purpose, a direct shear test of undisturbed expansive soil was carried out to measure its shear strength and water content. The relationship between the internal friction angle $\varphi$ and cohesion $c$ of expansive soil with the change of saturation $\mathrm{w}$ measured by the direct shear test is shown in the Figure 9 below:

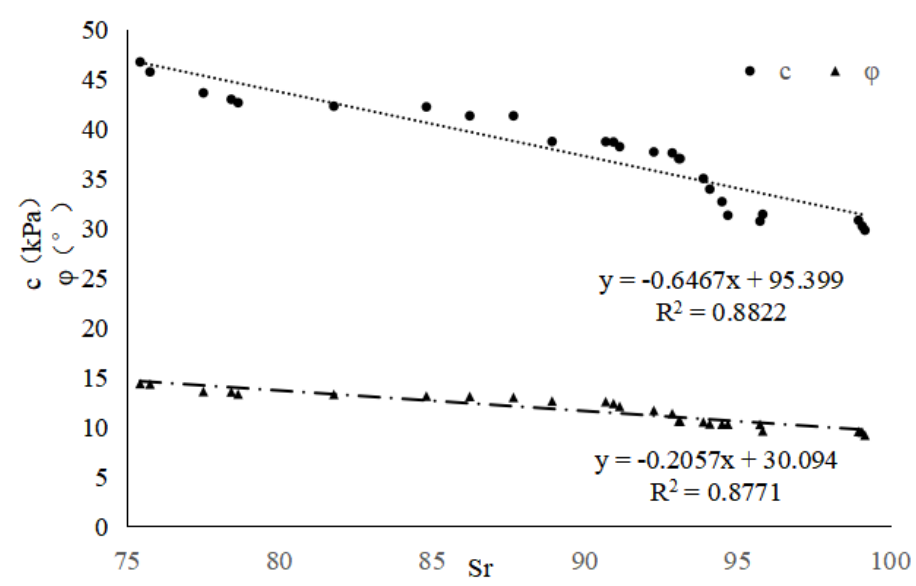

Figure 9. Relationship between soil strength and saturation.

The fitting formula of the relationship between intensity parameter and saturation $\mathrm{Sr}$ is as follows:

$$
\begin{aligned}
& C=-0.647 \times \mathrm{Sr}+95.4 \\
& \Phi=-0.206 \times \mathrm{Sr}+30.1 .
\end{aligned}
$$

It can be seen from the test results that the internal friction angle of the unweathered soil basically does not change with the water content, and it can be considered as a fixed value in the process of water absorption. The cohesion decreases significantly with increasing water content, and the data are 
more discrete. When the saturation is greater than $95 \%$, the cohesive force drops suddenly. Therefore, in the calculation process, when the saturation of the soil in the unweathered area is less than $95 \%$, the cohesion of the soil adopts the strength under natural conditions. When the saturation is greater than $95 \%$, the softening effect of the seepage should be considered, and the cohesive force should be set as a function of the saturation according to the fitting formula.

\section{Numerical Model}

\subsection{Geometric Model and Material Parameters}

According to engineering data, assuming a $15 \mathrm{~m}$ high expansive soil slope, the slope ratio is 1:2 (common slope ratio of expansive soil cutting slope). The thickness of the foundation soil is $10 \mathrm{~m}$, and the width of the slope top is $10 \mathrm{~m}$. The thickness of the weathered layer in the shallow layer affected by the dry and wet cycle is $2 \mathrm{~m}$, and the weathered layer below $2 \mathrm{~m}$ is unweathered soil. The thickness of the foundation is $10 \mathrm{~m}, 0 \sim 4 \mathrm{~m}$ is the same soil layer as the slope, and $4 \sim 10 \mathrm{~m}$ is the harder underlying clay layer. As shown in Figure 10 below.

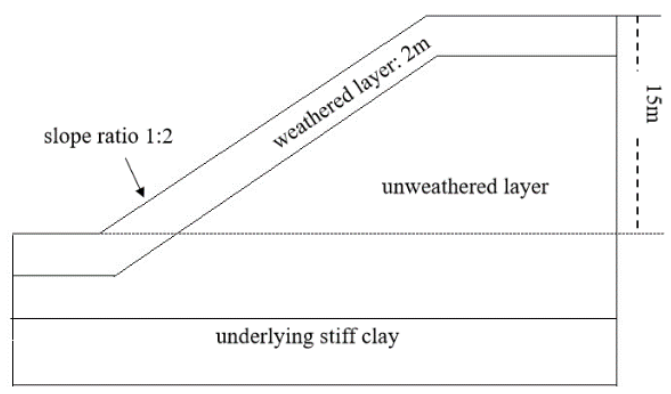

Figure 10. Slope geometry model.

The initial parameters of slope material are shown in the Table 3. With the increase of dry and wet cycles, the soil strength and permeability coefficient of the weathered layer are set according to the indoor test results.

Table 3. Soil parameters.

\begin{tabular}{ccc}
\hline Parameter & Slope & Underlying Clay \\
\hline $\mathrm{E}(\mathrm{MPa})$ & 15 & 25 \\
$\mathrm{~V}$ & 0.35 & 0.32 \\
$\gamma\left(\mathrm{kg} / \mathrm{m}^{3}\right)$ & 1900 & 2000 \\
$\mathrm{c}$ & 38.9 & 45 \\
$\varphi$ & 13.0 & 18 \\
$\mathrm{k}(\mathrm{cm} / \mathrm{s})$ & $1.1 \times 10^{-6}$ & $8.3 \times 10^{-7}$ \\
\hline
\end{tabular}

The soil water characteristic curve parameter of expansive soil is $2.2 \times 10^{4}$, parameter B is 0.5 , and porosity is 0.5 . The initial groundwater level is located on the ground, the bottom and both sides of the slope are set as impermeable boundaries, and the horizontal and vertical displacement of the bottom and the horizontal displacement of both sides are fixed.

\subsection{Inversion of Equivalent Moistening Expansion Coefficient}

The key of using endothermic expansion to simulate the effect of moistening expansion is to determine a reasonable expansion coefficient. Therefore, numerical simulation is carried out to determine the appropriate equivalent temperature and load boundary, and the expansion coefficient is obtained by inversion.

The equivalent endothermic expansion coefficient is retrieved by the following numerical model. The geometric size of the model is the size of the laboratory ring knife sample. In the load expansion 
test, the bottom of the sample is humidified with water, so the equivalent temperature at the bottom interface is set to $100^{\circ} \mathrm{C}$ (fully saturated state). The top of the sample is set to the equivalent temperature corresponding to the initial humidity. The $\mathrm{x}$-direction displacement of the left and right boundary, the $\mathrm{x}$-direction, and Y-direction of the bottom are constrained. The upper boundary load is set as $12.5 \mathrm{kpa}$ of the loaded expansion test.

In this test, 10 groups of swelling experiments were carried out with undisturbed expansive soil, and the average swelling rate was $2.13 \%$ (under the vertical load of $12.5 \mathrm{kPa}$ ).

The specific inversion process is as follows, the numerical model is shown in Figure 11:

1. Input a larger expansion coefficient to calculate the vertical expansion. Then, input a smaller expansion coefficient and calculate the vertical expansion again.

2. According to the measured expansion of geotechnical test, the expansion coefficient is estimated by interpolation, and the model is input to check whether the expansion is consistent with the measured value.

3. If it is consistent, the expansion coefficient shall be used as the equivalent moisture absorption expansion coefficient. If it is not consistent, it shall be further modified and recalculated until it is consistent with the measured expansion.

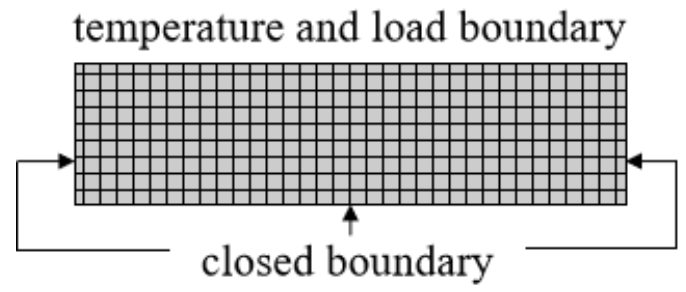

Figure 11. Numerical model for the inversion of expansion coefficient.

Prepare a batch of samples with the height of $20 \mathrm{~mm}$ and the initial saturation of $65 \%$. Carry out the expansion test under the vertical load of $12.5 \mathrm{kPa}$. The inversion results of equivalent expansion coefficient are shown in Table 4 . In the load expansion test, the moisture content of the sample increased by $10.75 \%$, which is equivalent to an equivalent temperature increase of 36.7 degrees. Through inversion, when the equivalent endothermic expansion coefficient is $1.02 \times 10^{-4}$, the calculated result of the endothermic expansion is consistent with the measured load expansion.

Table 4. Inversion of expansion coefficient.

\begin{tabular}{|c|c|c|c|}
\hline $\begin{array}{l}\text { Initial Water } \\
\text { Content }\end{array}$ & Final Water Content & Moisture Increase & Expansion Rate \\
\hline $25.75 \%$ & $36.5 \%$ & $10.75 \%$ & $2.13 \%$ \\
\hline equivalent & equivalent & temperature & Equivalent expansion \\
\hline temperature ${ }^{\circ} \mathrm{C}$ & temperature ${ }^{\circ} \mathrm{C}$ & increment ${ }^{\circ} \mathrm{C}$ & coefficient $1 /{ }^{\circ} \mathrm{C}$ \\
\hline 63.31 & 100 & 36.7 & $1.02 \times 10^{-4}$ \\
\hline
\end{tabular}

Similar studies have suggested that the equivalent expansion coefficient of expansive soil is generally between $1 \times 10^{-4} /{ }^{\circ} \mathrm{C}$ and $2 \times 10^{-4} /{ }^{\circ} \mathrm{C}$, and the results obtained are consistent with it.

\subsection{Analysis Steps}

In this paper, the model adopts the finite element method and develops a multi field coupling numerical calculation program based on FORTRAN language. The simplified calculation process of the program is shown in the Figure 12. 


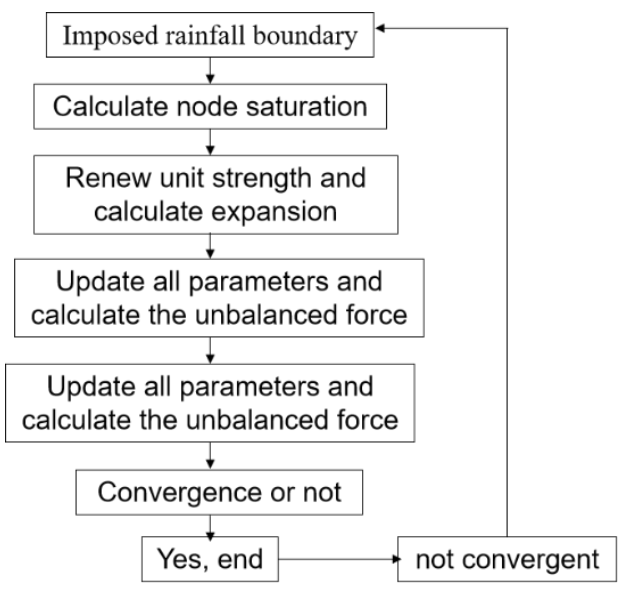

Figure 12. Simplified calculation flow chart of the program.

The calculation is divided into 3 steps:

1. The initial water level is at the bottom of the slope, and the initial pore pressure is linearly distributed according to the elevation. As shown in the Figure 13, the pore pressure at the top of the slope is $-150 \mathrm{kPa}$, and the initial geostress is balanced.
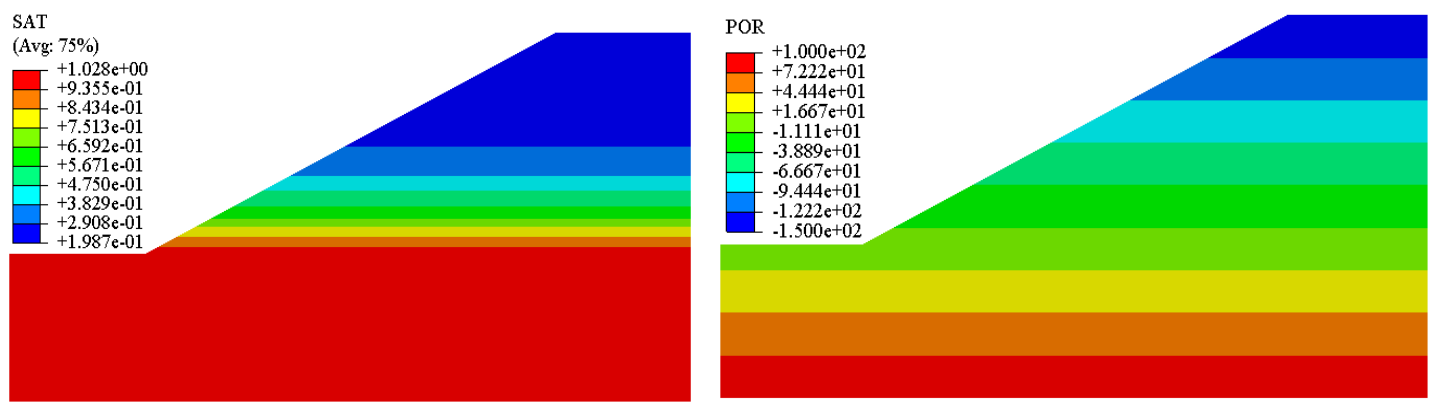

Figure 13. Initial saturation and pore pressure.

2. A flow boundary is applied to simulate the rainfall on the upper surface of the slope. To simulate the rainfall in the rainy season, a rainfall boundary as shown in the Table 5 is applied to the top and slope surfaces of the slope for a total of $72 \mathrm{~h}$.

Table 5. Rainfall intensity and duration.

\begin{tabular}{ccccc}
\hline Times (h) & $\mathbf{0}$ & $\mathbf{2 4}$ & $\mathbf{4 8}$ & $\mathbf{7 2}$ \\
\hline Rainfall $(\mathrm{mm} / \mathrm{h})$ & 0 & 20 & 20 & 0 \\
\hline
\end{tabular}

3. The amount of moistening absorption deformation is calculated based on the change of the humidity field of the slope caused by rainfall, the strain field is updated, and a new stress field is calculated based on the new strain field.

\section{Result Analysis}

\subsection{Impact of Rainfall on Slope Humidity Field}

Slope rainfall simulation is performed first. Figure 14 shows the saturation and pore pressure distribution of one dry-wet cycle slope after rainfall has just stopped. It can be seen from the Figure 14 that, during the rainfall process, as the wet front advances into the soil layer, the saturation zone moves 
up from the foot of the slope, and the weathering zone is more saturated than the unweathered zone. After rainfall decreases, the permeability coefficient of weathering zone is large, rainwater quickly infiltrates under its own weight, the surface soil saturation decreases, and the water content is lower than the inner soil. After the dry-wet cycle, the properties of the shallow expansive soil are very different from the underlying soil. Affected by heterogeneity, changes in water content mainly occur in shallow soil. Therefore, the moisture expansion and softening of expansive soil also mainly occur in shallow layers. The calculated results are consistent with unsaturated rainfall infiltration.
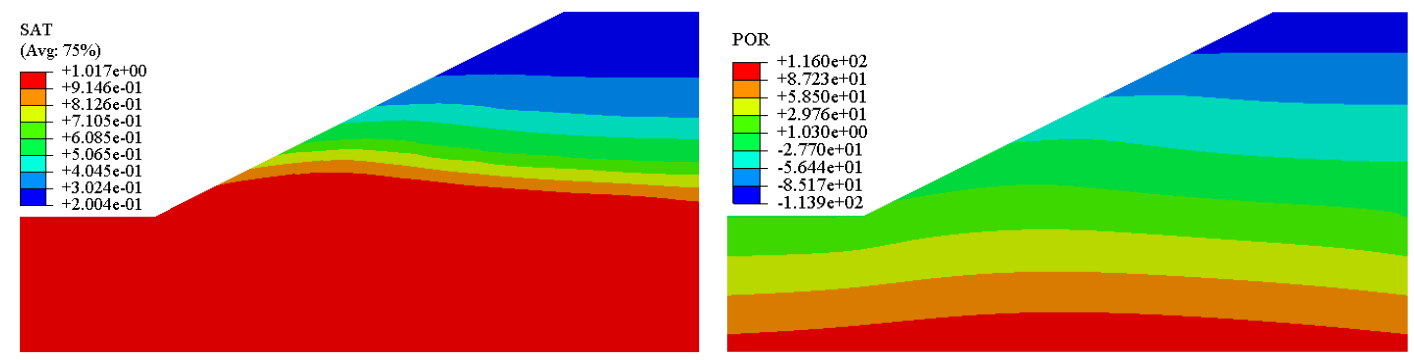

Figure 14. Saturation and pore pressure after rainfall.

\subsection{Failure Mode of Expansive Soil Slope}

According to the results of the existing dry-wet cycle test, the measured soil parameters after 0 5 are assigned to the weathering layer, and the overall displacement map of the expansive soil slope after the rainfall stops is shown below.

The analysis results are shown in Figure 15, the failure of unsaturated expansive soil slopes is not only caused by expansion deformation, but it also closely related to the strength parameters of the slope material. As the number of dry-wet cycles increases, the cohesion of the soil decreases significantly, the overall displacement of the slope increases, and the slip surface gradually becomes shallower.

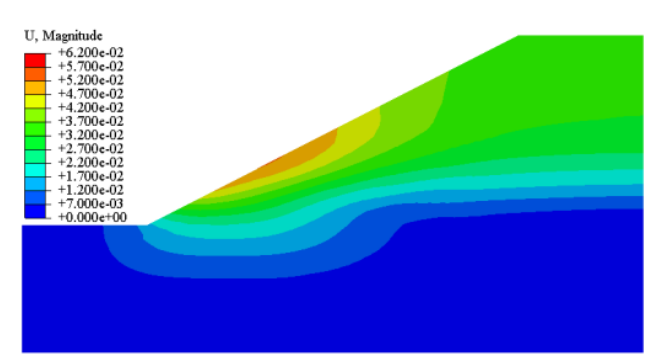

(a) 0 cycle

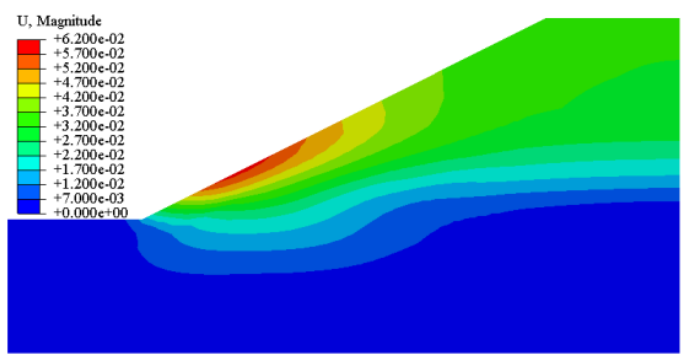

(c) 3 cycle

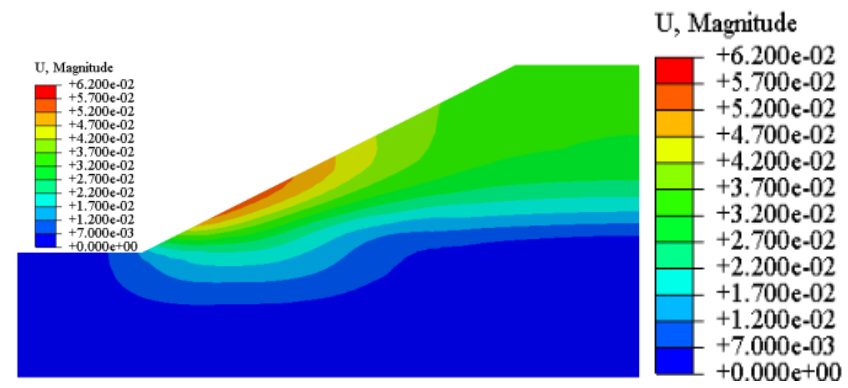

(b) 1 cycle

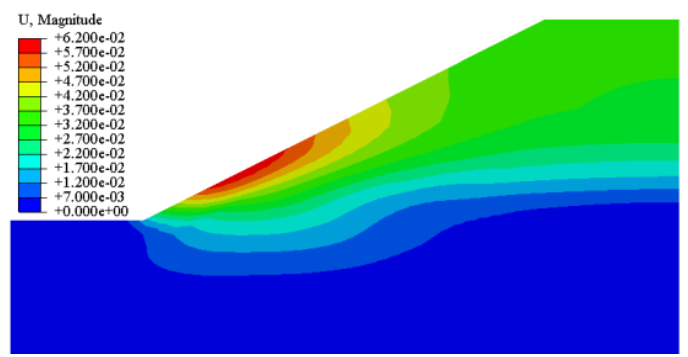

(d) 5 cycle

Figure 15. Displacement field after dry-wet cycle.

It can be seen from Figure 16 that the shallow layer of the lower half of the expansive soil slope has been deformed for several centimeters, so it can be considered that the shallow surface collapse 
has actually occurred. The calculation results show that the position of the sliding surface of the slope instability is located at the interface between the weathering layer (fractured zone) and the unweathered layer, running through the bottom of the fractured zone. Under the action of rainfall and dry-wet cycles, the landslide first appeared in the shallow part of the slope foot, and then the upper soil mass was caused to slide. According to the existing research [22-24], the expansive soil landslide is mainly shallow traction landslide, which is different from the circular sliding surface of ordinary cohesive soil $[25,26]$. Under the condition of heavy rainfall, the sliding surface of expansive soil tends to be shallower. Different from the circular slip surface of homogeneous cohesive soil slope, the slip surface of expansive soil slope shows shallow traction under the influence of heterogeneity.

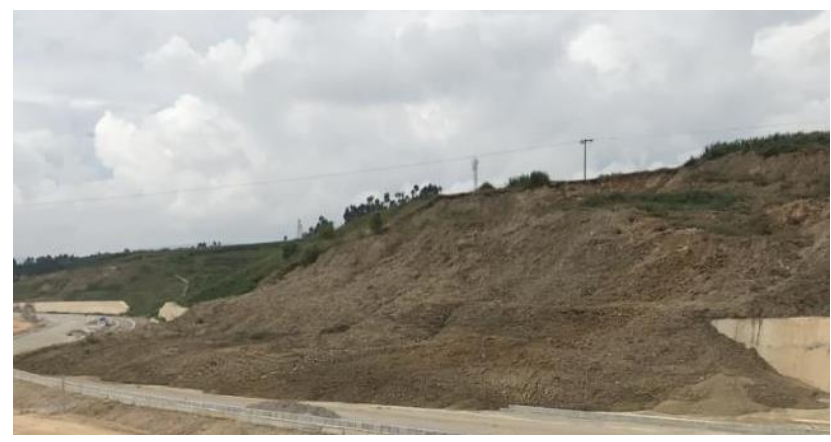

Figure 16. Typical sliding surface of expansive soil slope.

\subsection{Analysis of Overall Slope Stability}

Comparing the displacement and stability of common clay slopes without considering expansion, the differences are mainly in the following two points:

If the moistening expansion is neglected, the deformation calculated according to the common clay slope (without moistening expansion) is too small. When considering the moistening expansion, the displacement of the slope increases by an order of magnitude to several centimeters. When the actual expansive soil slope occurs landslide, the deformation is more than several centimeters. Therefore, the method considering moistening expansion is more practical.

As shown in the following Table 6, when considering the expansion deformation, the stability coefficient of the slope (calculated by strength reduction method) is significantly reduced. After only two wet and dry cycles, the slope is unstable and damaged. In fact, the expansive soil slope is often destroyed quickly after rainfall and intermittent period. The result of calculation explains this situation well. After rainfall, the weathering layer has a large displacement. Firstly, local sliding occurs in the shallow layer of the slope toe, which weakens the supporting force of the upper soil. Subsequently, the upper soil mass slides under traction, and the depth of sliding surface increases gradually. Finally, the failure mode similar to imbrication appears on the slope. This is consistent with the shallowness of expansive soil landslides. In practical engineering, the newly excavated slope exposed to air often landslides after 1-2 cycles of dry and wet in rainy season, which is well explained by the calculation results.

Table 6. Safety factor and maximum displacement.

\begin{tabular}{ccccc}
\hline \multirow{2}{*}{$\begin{array}{c}\text { Wet and Dry } \\
\text { Cycle Times }\end{array}$} & \multicolumn{2}{c}{ Consider Moistening Expansion } & \multicolumn{2}{c}{ Non-Moistening Expansion } \\
\cline { 2 - 5 } & $\begin{array}{c}\text { Maximum } \\
\text { Displacement }\end{array}$ & $\begin{array}{c}\text { Stability } \\
\text { Coefficient }\end{array}$ & $\begin{array}{c}\text { Maximum } \\
\text { Displacement }\end{array}$ & $\begin{array}{c}\text { Stability } \\
\text { Coefficient }\end{array}$ \\
\hline 0 & $5.23 \mathrm{~cm}$ & 1.21 & $0.54 \mathrm{~cm}$ & 1.89 \\
1 & $5.49 \mathrm{~cm}$ & 1.05 & $0.56 \mathrm{~cm}$ & 1.45 \\
2 & $5.76 \mathrm{~cm}$ & 0.97 & $0.57 \mathrm{~cm}$ & 1.41 \\
3 & $5.93 \mathrm{~cm}$ & 0.91 & $0.58 \mathrm{~cm}$ & 1.32 \\
5 & $6.08 \mathrm{~cm}$ & 0.89 & $0.61 \mathrm{~cm}$ & 1.15 \\
\hline
\end{tabular}




\subsection{Slope Stress}

In order to better analyze the stress evolution law during slope instability and failure, this section analyzes the stress change process of the expansive soil slope during the dry and wet cycle.

Since the potential sliding surface generally develops along the bottom of the weathering area, the bottom of the weathering area is selected as the monitoring section in the numerical simulation to further analyze the law of stress change, as shown in the Figure 17.

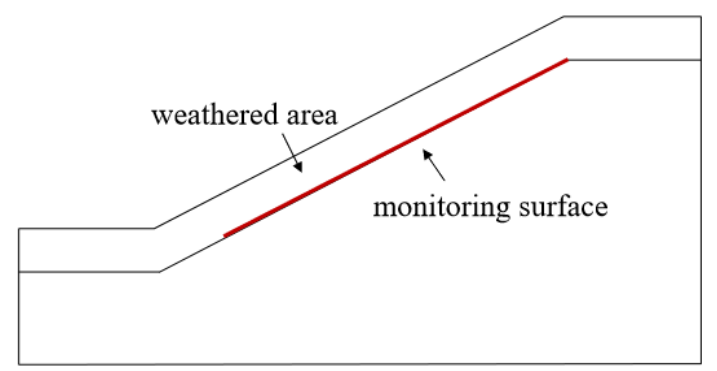

Figure 17. Monitoring surface of expansive soil slope (S11 is the horizontal stress; 222 is the vertical stress).

Figure 18 above shows the horizontal and vertical stress distribution at the monitoring section after a wet and dry cycle. Without considering the moistening expansion, the horizontal stress is uniformly distributed. After considering the moistening expansion, the horizontal stress in the lower half of the slope increased significantly, turning around at a height of about $8 \mathrm{~m}$, linearly increasing to several times, from $40 \mathrm{kPa}$ to $100 \mathrm{kPa}$. The location of the stress concentration roughly coincides with the range of the failure surface, which indicates that the increase of horizontal stress has a greater thrust on the slope soil, resulting in a larger displacement in this area. At the same time, the horizontal stress of the upper part of the slope is lower than that of the case without considering the moisture absorption expansion, which is due to the large displacement of the lower part of the soil mass, releasing part of the expansion force. From the monitoring of the distribution of vertical stress at the section, it is known that the vertical stress in the upper half of the slope is not significantly different from that without considering moistening expansion, and the vertical stress within $2 \mathrm{~m}$ above the slope bottom has increased by about $15 \mathrm{kPa}$.

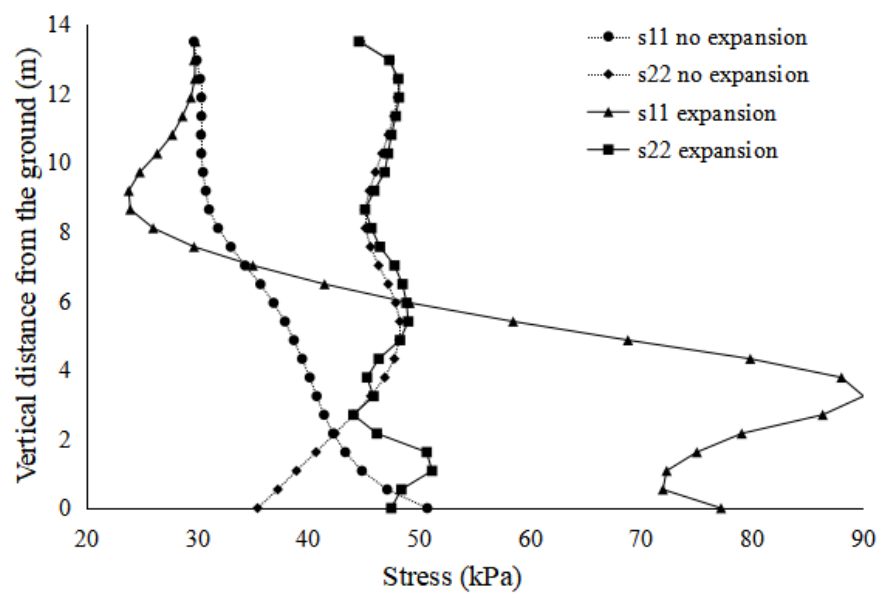

Figure 18. Stress of monitoring surface after one dry and wet cycle.

Figure 19 shows the horizontal stress distribution curve at the slope monitoring section after 0 to 5 dry-wet cycles. With the increase of the number of dry-wet cycles, the strength of the soil in the weathered area softens and yields, and the horizontal stress gradually decreases, but it is still significantly higher than the slope without moistening expansion. 


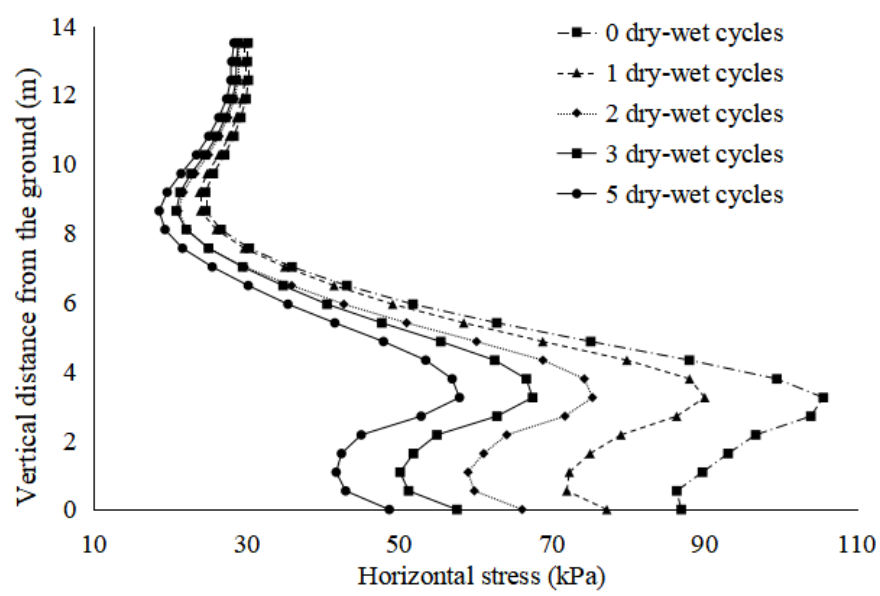

Figure 19. Horizontal stress of monitoring section.

In general, rainfall causes rainwater infiltration, and the water content of the lower part of the slope changes the most, resulting in the increase of horizontal stress several times. As the slope gradually displaces and collapses, the horizontal stress gradually releases. Therefore, the stress in the upper half of the slope is lower.

It can be seen from Figures 20 and 21 that the plastic strain of the expansive soil slope is increased several times compared with the slope without moistening expansion. If the expansion is not considered, no plastic zone appears on the slope after 3 cycles. After considering expansion, a large plastic deformation zone appeared at the bottom of the weathered layer at the foot of the slope after 3 cycles. The horizontal stress in the lower half of the slope rises sharply, causing stress concentration in this area and forming a large plastic area. The rise of shallow horizontal stress in the lower half of the slope and the evolving of the plastic zone along the bottom of the weathering layer are the main reasons for the shallow collapse.

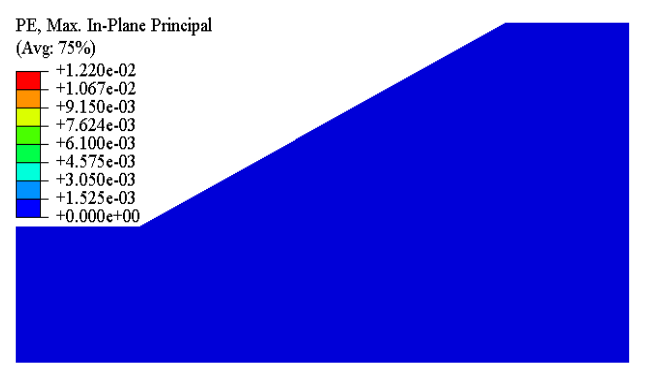

(a)

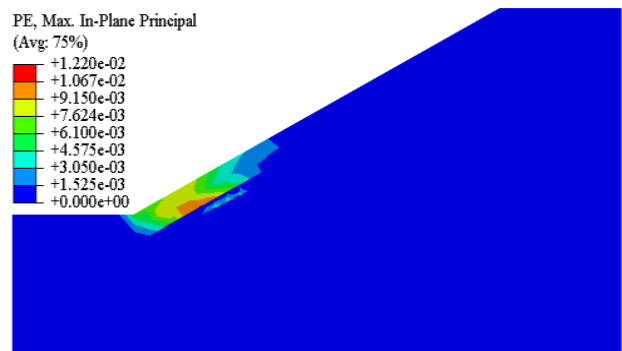

(b)

Figure 20. Plastic zone of slope after three cycles of drying and wetting: (a) moistening expansion is not considered; (b) moistening expansion is considered.

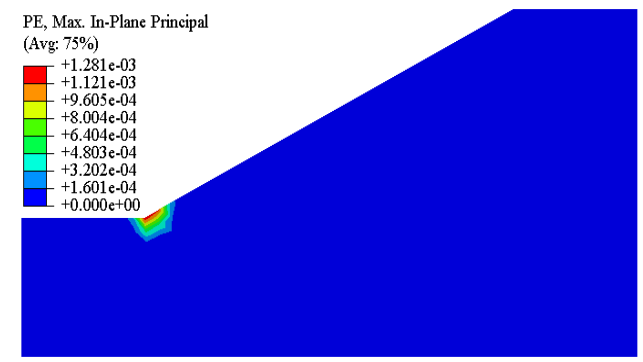

(a)

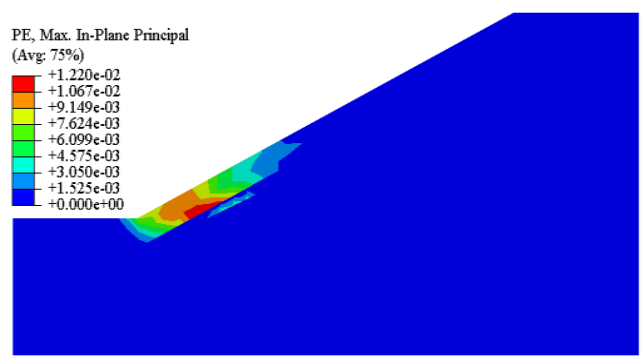

(b)

Figure 21. Plastic zone of slope after five cycles of drying and wetting: (a) moistening expansion is not considered; (b) di moistening expansion is considered. 


\section{Conclusions}

This study provides a numerical method for assessing the risk of landslides during soil excavation. The parameters in the model are obtained through laboratory tests. This method is well applied to the analysis of expansive soil slope in Yunnan Province, China. According to the research results, the main conclusions of this paper can be summarized as follows:

1. In this paper, the properties of expansive soil after dry-wet cycle are analyzed in detail. In the aspect of fracture development law, after the first to the second circulation, the surface fracture rate increases most obviously, and then tends to be stable gradually. In terms of strength and permeability, the dry-wet cycle mainly reduces strength and increases permeability by destroying the structure of expansive soil. After three cycles, the cohesion is reduced by half, the internal friction angle changes little, and the soil property is basically stable. At the same time, the permeability coefficient is increased by an order of magnitude.

2. The expansion and softening of expansive soil have a great influence on the slope stability after rainfall. Considering the influence of these two factors, the displacement of slope increases by an order of magnitude. From the change rule of stability coefficient, it can be seen that the expansive soil slope with good stability may lose stability after one or two rainfall.

3. According to the calculation, the sliding surface of the expansive soil slope develops along the bottom of the weathering zone. With the increase of the number of dry and wet cycles, the strength of expansive soil in the weathering area decreases, and the sliding surface becomes shallow. The results of calculation can explain the shallow and tractive properties of expansive soil landslide.

4. During rainfall infiltration, the saturation of the lower part of the slope changes the most. The effect of moistening expansion leads to a rapid rise in horizontal stress but little change in vertical stress. The large increase in horizontal stress is the main reason for slope failure.

5. In conclusion, in the construction of road slope in expansive soil area, construction in rainy season should be avoided as much as possible. Or take effective measures of slope water isolation, strictly control the amount of rainwater infiltration, and prevent the soil from further softening and expansion. In the next step of the analysis of expansive soil slope, it will be the research focus to conduct comprehensively statistical analysis [27] and adopt the updated method [28] to establish a quantitative model.

Author Contributions: S.Z.: Writing, original draft. Z.S.: Conceptualization, Super vision, Funding acquisition. M.P.: Project administration, Methodology, Formal analysis, Data curation, Writing. Y.B.: Field investigation, Formal analysis. All authors have read and agreed to the published version of the manuscript.

Funding: This research was funded by the National Natural Science Foundation of China (Grant No. 41731283, 41877234), National Key Research and Development Project (2019YFC1509702), and the Fundamental Research Funds for the Central Universities.

Conflicts of Interest: The authors declare no conflict of interest.

\section{References}

1. Yin, Z.Z.; Xu, B. Slope stability of expansive soil under fissure influence. Chin. J. Geotech. Eng. 2011, 33, 454-459. (In Chinese)

2. Wu, J.; Yuan, J.; Yang, S.; Lu, T. Experimental study on swell-shrinking performance of expansive soil under wetting-drying cycles. Adv. Sci. Technol. Water Resour. 2013, 33, 62-65. (In Chinese)

3. Yang, H.P.; Tang, X.Y.; Liao, Y.L. Laboratory Research on Relationship between Swelling Force and Allowable Deformation. In Advanced Materials Research; Trans Tech Publications Ltd.: Bäch, Switzerland, 2011; Volume 255, pp. 529-533.

4. Ng, C.W.W.; Zhan, L.T.; Bao, C.G.; Fredlund, D.G.; Gong, B.W. Performance of an unsaturated expansive soil slope subjected to artificial rainfall infiltration. Géotechnique 2003, 53, 143-157. [CrossRef] 
5. Zhan, L.T.; Ng Charles, W.W.; Fredlund Del, G. Field study of rainfall infiltration into a grassed unsaturated expansive soil slope. Can. Geotech. J. 2007, 44, 392-408. [CrossRef]

6. Greco, R.; Guida, A.; Damiano, E.; Olivares, L. Soil water content and suction monitoring in model slopes for shallow flowslides early warning applications. Phys. Chem. Earth Parts 2010, 35, 127-136. [CrossRef]

7. Wang, G.L.; Chen, S.S.; Xu, G.M. Centrifuge model test on stability of expansive soil slope under alternation between drying and wetting. Hydro-Sci. Eng. 2005, 4, 6-10. (In Chinese)

8. Yin, Z.Z.; Yuan, J.P.; Wei, J.; Cao, X.S. On the influence of fissures on the stability of expansive soil slope. J. Geotech. Eng. 2012, 34, 2155-2167. (In Chinese)

9. Zhan, L.; Cheng, J.H.; Ding, X.B. Physical model tests of expansive soil slope. Chin. J. Geotech. Eng. 2013, 36, 731-740. (In Chinese)

10. Alonso, E.E.; Gens, A.; Josa, A. A constitutive model for partially saturated soils. Geotechnique 1990, 40, 405-430. [CrossRef]

11. Alonso, E.E.; Vaunat, J.; Gens, A. Modelling the mechanical behaviour of expansive clays. Eng. Geol. 1999, 54, 173-183. [CrossRef]

12. Qi, S.; Vanapalli, S.K. Hydro-mechanical coupling effect on surficial layer stability of unsaturated expansive soil slopes. Comput. Geotech. 2015, 70, 68-82. [CrossRef]

13. Sun, J.C.; Wang, G.Q.; Dong, X.B.; Huang, Y.F.; Gao, Q.C. Expansive model and back analysis of expansive soil. Rock Soil Mech. 2007, 28, 2055-2059. (In Chinese)

14. Hicks, M.A.; Samy, K. Influence of heterogeneity on undrained clay slope stability. Q. J. Eng. Geol. Hydrogeol. 2002, 35, 41-49. [CrossRef]

15. Hicks, M.A.; Spencer, W.A. Influence of heterogeneity on the reliability and failure of a long 3D slope. Comput. Geotech. 2010, 37, 948-955. [CrossRef]

16. Lewandowska, J.; Szymkiewicz, A.; Burzyński, K.; Vauclin, M. Modeling of unsaturated water flow in double-porosity soils by the homogenization approach. Adv. Water Resour. 2004, 27, 283-296. [CrossRef]

17. Bishop, A.W.; Blight, G.E. Some Aspects of Effective Stress in Saturated and Partly Saturated Soils. Geotechnique 1963, 13, 177-197. [CrossRef]

18. Van Genuchten, M.T. A Closed-form Equation for Predicting the Hydraulic Conductivity of Unsaturated Soils1. Soil Sci. Soc. Am. J. 1980, 44, 892. [CrossRef]

19. Sun, D.A.; Huang, D.J. Soil water and deformation characteristics of Nanyang expansive soil under dry wet cycle. Geotech. Mech. 2015, 36, 123-127. (In Chinese)

20. Fredlund, D.G.; Rahardjo, H. Soil Mechanics for Unsaturated Soils; Wiley: Hoboken, NJ, USA, 1993.

21. Lu, A.H.; Mao, X.B. Numerical simulation of humidity stress field. J. Rock Mech. Eng. 2002, 021, $2470-2473$. (In Chinese)

22. Hicks, M.A.; Nuttall, J.D.; Chen, J. Influence of heterogeneity on 3D slope reliability and failure consequence. Comput. Geotech. 2014, 61, 198-208. [CrossRef]

23. Wu, C.-Y.; Yeh, Y.-C. A Landslide Probability Model Based on a Long-Term Landslide Inventory and Rainfall Factors. Water 2020, 12, 937. [CrossRef]

24. He, S.; Wang, J.; Liu, S. Rainfall Event-Duration Thresholds for Landslide Occurrences in China. Water 2020, 12, 494. [CrossRef]

25. Roccati, A.; Faccini, F.; Luino, F.; Ciampalini, A.; Turconi, L. Heavy Rainfall Triggering Shallow Landslides: A Susceptibility Assessment by a GIS-Approach in a Ligurian Apennine Catchment (Italy). Water 2019, 11, 605. [CrossRef]

26. Chan, H.-C.; Chen, P.-A.; Lee, J.-T. Rainfall-Induced Landslide Susceptibility Using a Rainfall-Runoff Model and Logistic Regression. Water 2018, 10, 1354. [CrossRef]

27. Shen, D.; Shi, Z.; Peng, M.; Zhang, L.M. Longevity analysis of landslide dams. Landslides. 2020. Available online: https://doi.org/10.1007/s10346-020-01386-7 (accessed on 1 April 2020).

28. Zhang, F.S.; Wang, T.; Liu, F.; Peng, M.; Furtney, J.; Zhang, L.M. Modeling of Fluid-particle Interaction by Coupling the Discrete Element Method with a Dynamic Fluid Mesh: Implications to Suffusion in Gap-graded Soils. Comput. Geotechni. 2020, 124, 103617. [CrossRef]

(C) 2020 by the authors. Licensee MDPI, Basel, Switzerland. This article is an open access article distributed under the terms and conditions of the Creative Commons Attribution (CC BY) license (http://creativecommons.org/licenses/by/4.0/). 